\title{
Maternal complementary feeding practices and anthropometric status of children (6-23 months) in Abakaliki Nigeria, a facility-based study
}

Linda Obianuju Edafioghor ${ }^{1}$, Uzoma Vivian Asiegbu ${ }^{2,3}$, Chinonyelum Thecla Ezeonu ${ }^{2,3}$, Gideon Onyedikachi Iheme ${ }^{4}$, Haadi Marufat Adeduntan ${ }^{5}$, Ifeyinwa Adaora Ekwueme ${ }^{6}$

${ }^{1}$ Department of Nutrition and Dietetics, Federal Medical Centre Asaba Nigeria

${ }^{2}$ Department of Paediatrics, Alex-Ekwueme Federal University Teaching Hospital, Abakaliki

Nigeria

${ }^{3}$ Institute of Child Health, Alex-Ekwueme Federal University Teaching Hospital, Abakaliki

Nigeria

${ }^{4}$ Department of Human Nutrition and Dietetics, Michael Okpara University of Agriculture Umudike, Abia state, Nigeria

${ }^{5}$ Department of Nutrition and Dietetics, Alex-Ekwueme Federal University Teaching Hospital, Abakaliki Nigeria

${ }^{6}$ Department of Nutrition and Dietetics, Federal Medical Centre, Jabi Airport Road Abuja.

Corresponding Author: Linda Obianuju Edafioghor, Department of Nutrition and Dietetics, Federal Medical Centre Asaba, P.M.B. 1033 Asaba Delta State Nigeria.

juliegreat24@yahoo.com

Funding/ Support: None

Conflict of Interest: None

Authorship Contribution:

L.O.E, U.V.A, C.T.E and G.O.I were responsible for the formulation of research concept and design. H.M.A and I.A.E contributed to the acquisition and screening of data. L.O.E and G.O.I were responsible for the statistical analysis. L.O.E and G.O.I drafted the manuscript while C.T.E and U.V.A critically reviewed the manuscript.

Availability of Data and Materials:

The dataset that supports the results and findings of this research is available from the corresponding author, upon reasonable request. 


\section{ABSTRACT}

Sub-optimal complementary feeding practices among children aged 6-23 months is a major cause of under-nutrition in developing countries. This study was designed to assess the complementary feeding practices and nutritional status of children 6-23 months attending an immunization clinic at Alex-Ekwueme Federal University Teaching Hospital, Abakaliki, Nigeria. The study was descriptive and cross-sectional in design. A total of 320 children were selected using a two-stage sampling technique. WHO/PAHO/UNICEF recommendations and WHO Child Growth Standard charts were used to categorize their complementary feeding and anthropometric indices, respectively. Statistical analysis was performed using descriptive statistics and inferential statistics. Complementary feeding indicators such as timely complementary feed introduction (54.1\%) and minimum dietary diversity $(68.7 \%)$ were met by more than half of the respondents. But overall, complementary feeding practices were considerably poor. Low minimum meal frequency, minimum adequate diet and continued breastfeeding at one year were reported. Wasting, stunting and underweight prevalences were $12.5 \%, 11.3 \%$ and $8.3 \%$ respectively. Children who continued breastfeeding at one year (AOR $=$ $0.34 ; \mathrm{CI}=0.15-0.76)$ or met minimum dietary diversity criteria $(\mathrm{AOR}=0.43 ; \mathrm{CI}=0.17-1.05)$ were less likely to be stunted. Increased attention towards breastfeeding continuation and dietary diversity improvement using locally available/affordable food stuffs is needed.

Keywords: Complementary feeding, anthropometry, children aged 6-23 months, Nigeria

\section{INTRODUCTION}

Adequate nutrition during infancy and childhood is essential to ensure the growth, health and development of children to their full potential (WHO, 2009). The age of 6-23 months old is the longest period in the "first 1,000 days" of life. This period is called the window of opportunity and is the important stage to optimize child growth and development to prevent malnutrition, including wasting, underweight and stunting, as well as their negative consequences in adulthood (Dewey and Vitta, 2013).

Although complementary feeding is a universal practice, the methods and manner in which it is practiced vary between cultures, individuals and socioeconomic classes. In a typical developing nation, they are often characterized by poor feeding practices and poor dietary quality of homemade complementary foods (Dewey and Adu-Afarwuah, 2008; Krebs et al., 2011; Plessis et al., 2013). Another concern is that the early introduction of complementary goods before the age of six months can lead to displacement of breast milk and increased risk of infections such as diarrhea which further contributes to weight loss and malnutrition (Aggarwal et al., 2008). The World Health Organization also reported that less than one-fourth of children aged 6-23 months met the minimum acceptable diet (MAD), dietary diversity and meal frequency standards in these countries (WHO, 2018). In Nigeria, this is confirmed by reports from Federal Ministry of Health (2005) which revealed that over 50\% infants are given complementary foods before six months and these foods are often of poor nutritional value.

Malnutrition is an underlying contributor to up to $45 \%$ of under-five deaths (WHO, 2014). Reports from various parts of the developing world have revealed a high prevalence of childhood malnutrition (Odunayo and Oyewole, 2006; Sarkar et al., 2013) and the prominent role 
of malnutrition as a major contributor to under-five deaths (Krishnan et al., 2012). According to the 2018 Nigeria Demographic and Health Survey, 37\%, 27.2\% and 23.0\% of under-5 children are stunted, wasting and underweight respectively (National Population Commission and ICF, 2019).

Growth faltering as a result of inadequacy of complementary food in terms of quality, quantity and frequency of meals has been reported (Awobgenja and Ugwuona, 2010; Kruger and Gericke, 2003; Mushaphi et al., 2008). Inappropriate infant feeding practices and family characteristics, which do not support or promote appropriate breastfeeding have been identified as risk factors for malnutrition. (Lawoyin et al., 2003; Amsalu and Tigabu, 2008; Jamro et al., 2012). Addressing the influence of complementary feeding practice of mothers on nutritional status of children may be a key strategy towards the reduction of the burden of child malnutrition.

Complementary feeding practices and nutritional status in Nigeria are well documented (Omotoye and Adesanmi, 2019; Sosanya et al., 2019; Ibrahim et al., 2019; Tobi et al., 2019; Oluwaseyi et al., 2019; Yusuf and Jibrin, 2020), however there is a dearth of recent evidence in Southeast Nigeria (Ayogu et al., 2015; Okereke et al., 2015; Ndiokwelu et al., 2014). Also, a good number of these local studies failed to apply either the revised WHO infant and young child feeding recommendations or the WHO 2006 growth reference in their data generation (Iheme et al., 2021). Therefore this study will add to the existing but limited body of knowledge to provide evidence on complementary feeding practices and anthropometric status of children in South East Nigeria using current and universally accepted indicators and guidelines. It will also explore which infant feeding factors are most closely associated with malnutrition.

\section{MATERIALS AND METHODS Study Design and Population}

A descriptive cross sectional survey design was employed. The population for this study consisted of mothers and their children (aged 6-23 months) accessing child welfare services at Institute of Child Health in Alex-Ekwueme Federal University Teaching Hospital, Abakaliki Nigeria.

\section{Sampling}

The Yamane (1967) formula was used to determine the sample size:

$\mathrm{N}=\mathrm{z} 2 \mathrm{P}(1-\mathrm{P})$

$\mathrm{d} 2$

$\mathrm{N}=$ minimum sample size.

$\mathrm{Z}=$ the standard normal deviation set at 1.96 which corresponds to a $9.5 \%$ confidence level.

$\mathrm{P}=$ the expected proportion of individuals in the target population estimated to have the characteristics of interest - Prevalence of underweight children (aged 6-23 months) in Nigeria-$22.9 \%$ (NPC and ICF, 2019).

$\mathrm{d}=$ degree of precision $5 \%$

Minimum sample size $\mathrm{N}=271$.

A total of 320 respondents were selected using a two stage sampling technique. The Institute of Child Health Clinic, Alex Ekwueme Federal University Teaching Abakaliki was purposively selected given that it is one of the major centres for immunisation and other child welfare 
services for pediatrics in South East Nigeria. A random sampling (balloting without replacement) technique was used to select the eligible infants and young children.

\section{Ethical Considerations}

Approval for the study was sought and an approval number obtained from the Research and Ethics Committee of Alex Ekwueme Federal University Teaching Hospital, Abakaliki (AEFUTHA/REC/VOL 3/2020/107). Verbal informed consent was obtained from the mothers after the objectives of the study, assurance of no harm, confidentiality and freedom to end their participation were clearly communicated to them.

\section{Data Collection}

Data for this study were collected with using an interviewer-administered structured questionnaire. The questionnaire was used to obtain information on the mother's socio economic and demographic data, and child feeding practices and anthropometric status was then assessed.

Weight was measured in kilograms at $0.01 \mathrm{~kg}$ accuracy where a UNICEF Salter Scale Model 235 was used. Since this study was carried out in a child welfare clinic, all the children had their ages recorded in child health cards. The length of the child was measured in centimeters using a pediatric height board of standard design (SECA) with 0.1 centimeter accuracy.

Pretesting was done with 16 (5\%) mothers and their children (aged 6-23 months) in the study area (not included in the study data) to refine the content and approach of the questionnaire. Data collection took place between November 2020 and January 2021.

\section{Definitions and Statistical Analysis}

Complementary feeding practices adopted the following recommendation of PAHO et al. (2013) for infant and young child feeding (IYCF):

1) Prolonged/continued breastfeeding (PBF); the child was still breastfed at 1 year.

2) Timely introduction to complementary feeding; the child was given solid, semi-solid and liquid food at the age of 6 months.

3) Minimum dietary diversity (MDD); the child aged 6-23 months received complementary foods from $\geq 4$ out of 7 food groups.

4) Minimum meal frequency (MMF); the child aged 6-23 months received a meal with standard frequency taking into account the breastfeeding status.

5) The child aged 6-23 months received meals that met both the standard for minimum dietary diversity and minimum meal frequency (MAD).

Severe malnutrition was defined as $\mathrm{Z}$ score $<3$ and moderate as $\mathrm{Z}$ score $<2$. Data analysis on anthropometry was conducted using the WHO Anthro 2005 v.2.0.4 software. The Z-score was used to categorise the anthropometric status of respondents (WHO, 2006). This classification applies to weight for age, weight for length/height, and height for age indices.

All statistical analysis was done using Statistical Package for the Social Sciences (SPSS) for Windows, version 25. Descriptive statistics (mean, frequency and percentage) were computed for 
the categorised and continuous variables. Logistic regression was used to determine the association between maternal complementary feeding practices and the anthropometric status of their children.

\section{RESULTS}

Table 1 indicates the socio-economic characteristics of mothers. A majority $(77.5 \%)$ of the mothers were aged 26-35years. Most (64.4\%) of them had less than 3 children. Maternal educational and occupational status revealed a preponderance of tertiary education holders $(69.7 \%)$ and civil/public servants $(40.9 \%)$. Income levels per month ranged from $\$ 25,000$ $100,000(\$ 61.0-244.0)$ amongst $45.9 \%$ of the respondents.

Table 1. Socio-economic characteristics of the mothers

\begin{tabular}{|c|c|c|}
\hline Variables & Frequency $(\mathrm{N}=\mathbf{3 2 0})$ & Percentage (\%) \\
\hline \multicolumn{3}{|l|}{ Age } \\
\hline 25 years & 45 & 14.1 \\
\hline 26-35years & 248 & 77.5 \\
\hline $36-45$ years & 27 & 8.4 \\
\hline \multicolumn{3}{|l|}{ Marital status } \\
\hline Single & 12 & 3.8 \\
\hline Married & 307 & 95.9 \\
\hline Divorced/separated & 1 & 0.3 \\
\hline \multicolumn{3}{|l|}{ Ethnic group } \\
\hline Yoruba & 10 & 3.1 \\
\hline Igbo & 293 & 91.6 \\
\hline Hausa & 7 & 2.2 \\
\hline Others & 10 & 3.1 \\
\hline \multicolumn{3}{|l|}{ Number of children } \\
\hline$<3$ & 206 & 64.4 \\
\hline $3-5$ & 104 & 32.5 \\
\hline $6-8$ & 10 & 3.1 \\
\hline \multicolumn{3}{|c|}{ Education qualification } \\
\hline No formal education & 1 & 0.3 \\
\hline Primary & 13 & 4.1 \\
\hline Secondary & 83 & 25.9 \\
\hline Tertiary & 223 & 69.7 \\
\hline \multicolumn{3}{|l|}{ Occupation } \\
\hline Civil/public servant & 132 & 40.9 \\
\hline Farmers & 9 & 2.8 \\
\hline Traders & 69 & 21.6 \\
\hline Artisan & 25 & 7.8 \\
\hline House wife & 86 & 26.9 \\
\hline \multicolumn{3}{|c|}{ Monthly household income } \\
\hline$<25,000$ & 121 & 37.8 \\
\hline $25,000-100,000$ & 147 & 45.9 \\
\hline $101,000-250,000$ & 44 & 13.8 \\
\hline$>250,000$ & 8 & 2.5 \\
\hline
\end{tabular}


Figure 1 shows the IYCF practices of children aged 6-23 months. Continued breastfeeding at 1 year was reported in a minority $(30.8 \%)$ of the respondents. More than half $(54.1 \%)$ of them introduced complementary foods begining at 6 months of age. Furthermore, $68.7 \%, 43.4 \%$ and $25.9 \%$ met the minimum criteria for meal frequency, dietary diversity and adequate diet respectively.

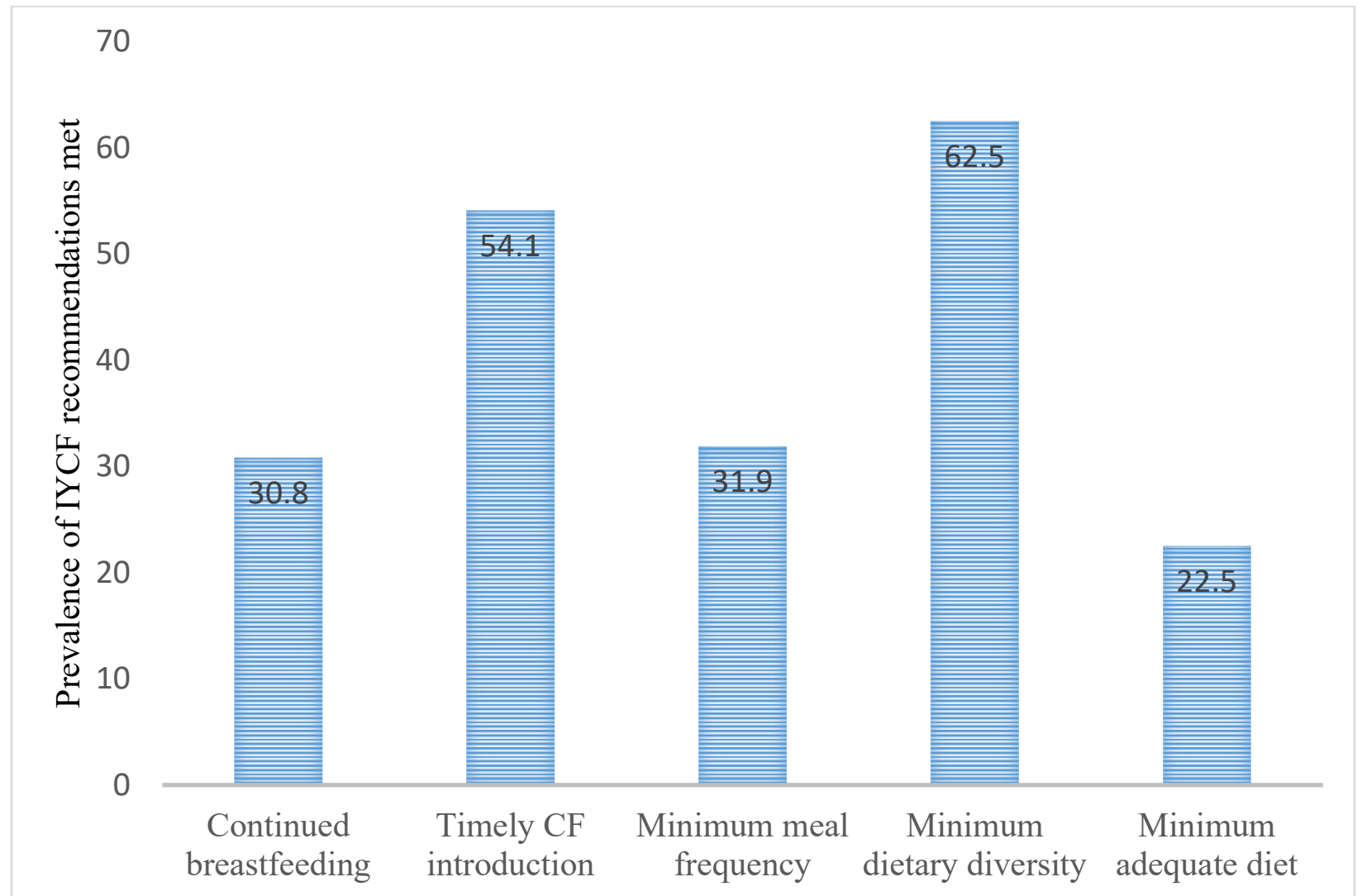

Figure 1. IYCF feeding practices of children aged 6-23 months

Table 2 provides results on anthropometry by sex classification of the respondents. Overall, more than a tenth of the respondents had wasted infants/children (12.5\%) and stunted infants/children $(11.3 \%) ; 8.3 \%$ were underweight. The prevalence of wasting was higher in boys $(13.3 \%)$ than in girls (11.7\%). Similarly, there were more stunted and underweight males (Stunting- 13.9\%; Underweight- 10.5\%) than their female counterparts (Stunting - 8.6\%; Underweight - 6.2\%).

Table 3 shows the anthropometric status of respondents across the various age groups. Results revealed the preponderance of wasting in infants aged 6-8 (14.9\%) and 9-8 months (15.2\%) than their older counterparts aged 13-23 months (3.0\%). The prevalence of stunting was highest in 1323 months old children (21.3\%) followed by 6-8 (10.7\%) and 9-12 months (6.4\%) infants. Underweight prevalence was reported as $7.7 \%, 8.8 \%$ and $7.7 \%$ in the three age groups, respectively. 
Table 2. Gender distribution of the children's anthropometric status

\begin{tabular}{lllllll}
\hline Variables & Male & $(\mathbf{N}=\mathbf{1 5 8})$ & \multicolumn{2}{c}{ Female $(\mathbf{N}=\mathbf{1 6 2})$} & \multicolumn{2}{c}{ Total $(\mathbf{N}=\mathbf{3 2 0})$} \\
& F & \% & F & \% & F & \% \\
\hline Weight for length (WHZ) & & & & & & \\
Severely wasted & 11 & 7.0 & 7 & 4.3 & 18 & 5.6 \\
Moderately wasted & 10 & 6.3 & 12 & 7.4 & 22 & 6.9 \\
Normal & 123 & 77.8 & 130 & 80.2 & 253 & 79.1 \\
Overweight/obese & 14 & 8.9 & 13 & 8.0 & 27 & 8.4 \\
Total & 158 & 100.0 & 162 & 100.0 & 320 & 100.0 \\
Height for age (HAZ) & & & & & & \\
Severely stunted & 7 & 4.4 & 7 & 4.3 & 14 & 4.4 \\
Moderately stunted & 15 & 9.5 & 7 & 4.3 & 22 & 6.9 \\
Normal & 136 & 86.1 & 148 & 91.4 & 284 & 88.8 \\
Total & 158 & 100.0 & 162 & 100.0 & 320 & 100.0 \\
Weight for age & & & & & & \\
Severely underweight & 6 & 3.8 & 3 & 1.9 & 9 & 2.8 \\
Moderately underweight & 10 & 6.3 & 7 & 4.3 & 17 & 5.3 \\
Normal & 128 & 81.0 & 139 & 85.8 & 267 & 83.4 \\
Overweight/obese & 14 & 8.9 & 13 & 8.0 & 27 & 8.4 \\
Total & 158 & 100.0 & 162 & 100.0 & 320 & 100.0 \\
\hline
\end{tabular}

Table 3. Anthropometric status of respondents across various age groups

\begin{tabular}{|c|c|c|c|c|c|c|c|c|}
\hline \multirow[t]{2}{*}{ Variables } & \multicolumn{2}{|c|}{$\begin{array}{l}\text { 6-8 months } \\
(\mathrm{N}=130)\end{array}$} & \multicolumn{2}{|c|}{$\begin{array}{l}\text { 9-12 months } \\
(\mathrm{N}=125)\end{array}$} & \multicolumn{2}{|c|}{$\begin{array}{l}\text { 13-23 month } \\
(\mathrm{N}=65)\end{array}$} & \multicolumn{2}{|c|}{ Total $(\mathrm{N}=320)$} \\
\hline & $\mathbf{F}$ & $\%$ & $\mathbf{F}$ & $\%$ & $\mathbf{F}$ & $\%$ & $\mathbf{F}$ & $\%$ \\
\hline \multicolumn{9}{|l|}{$\begin{array}{l}\text { Weight for length } \\
\text { (WHZ) }\end{array}$} \\
\hline Severely wasted & 9 & 6.9 & 8 & 6.4 & 1 & 1.5 & 18 & 5.6 \\
\hline Moderately wasted & 10 & 7.7 & 11 & 8.8 & 1 & 1.5 & 22 & 6.9 \\
\hline Normal & 107 & 82.3 & 99 & 79.2 & 47 & 72.3 & 253 & 79.1 \\
\hline Overweight/obese & 4 & 3.1 & 7 & 5.6 & 16 & 24.6 & 27 & 8.4 \\
\hline Total & 130 & 100.0 & 125 & 100.0 & 65 & 100.0 & 320 & 100.0 \\
\hline \multicolumn{9}{|l|}{ Height for age (HAZ) } \\
\hline Severely stunted & 2 & 1.5 & 6 & 4.8 & 6 & 9.2 & 14 & 4.4 \\
\hline Moderately stunted & 12 & 9.2 & 2 & 1.6 & 8 & 12.3 & 22 & 6.9 \\
\hline Normal & 116 & 89.2 & 117 & 93.6 & 51 & 78.5 & 284 & 88.8 \\
\hline Total & 130 & 100.0 & 125 & 100.0 & 65 & 100.0 & 320 & 100.0 \\
\hline \multicolumn{9}{|l|}{ Weight for age } \\
\hline Severely underweight & 3 & 2.3 & 5 & 4.0 & 1 & 1.5 & 9 & 2.8 \\
\hline Moderately underweight & 7 & 5.4 & 6 & 4.8 & 4 & 6.2 & 17 & 5.3 \\
\hline Normal & 116 & 89.2 & 101 & 80.8 & 50 & 76.9 & 267 & 83.4 \\
\hline Overweight/obese & 4 & 3.1 & 13 & 10.4 & 10 & 15.4 & 27 & 8.4 \\
\hline Total & 130 & 100.0 & 125 & 100.0 & 65 & 100.0 & 320 & 100.0 \\
\hline
\end{tabular}


Table 4 shows the results of the adjusted logistic regressions for under-nutrition and complementary feeding indicators. Complementary feeding practice variables were not significantly associated with wasting and underweight. The odds of stunting among children still breastfed at one year were $66 \%$ lower than children not breastfed at one year (AOR $=0.34$; $95 \% \mathrm{CI}-0.15,0.76)$. Also, children who met minimum dietary diversity criteria were less likely to be stunted than those who did not $(\mathrm{AOR}=0.43 ; 95 \% \mathrm{CI}-0.17,1.05)$.

Table 4. Association between complementary feeding practice variables and under-nutrition among children 6-23 months of age

\begin{tabular}{lcccccc}
\hline & \multicolumn{2}{c}{ Wasting } & \multicolumn{2}{c}{ Underweight } & \multicolumn{2}{c}{ Stunting } \\
& AOR & $\mathbf{9 5 \%}$ CI & AOR & 95\% CI & AOR & 95\% CI \\
\hline $\begin{array}{l}\text { Complementary feeding } \\
\text { variables }\end{array}$ & & & & & & \\
$\begin{array}{l}\text { Continued breastfeeding } \\
(\mathrm{N}=65)\end{array}$ & 2.43 & $0.81-7.23$ & 1.82 & $0.52-6.45$ & $0.34^{* *}$ & $0.15-0.76$ \\
$\begin{array}{l}\text { Timely complementary } \\
\text { feed introduction (N=320) }\end{array}$ & 1.32 & $0.67-2.59$ & 0.99 & $0.44-2.21$ & 0.645 & $0.32-1.30$ \\
$\begin{array}{l}\text { Minimum Dietary diversity } \\
(\mathrm{N}=320)\end{array}$ & 1.01 & $0.47-2.19$ & 0.87 & $0.30-2.52$ & $0.43^{*}$ & $0.17-1.05$ \\
$\begin{array}{l}\text { Minimum meal frequency } \\
\text { (N=320) }\end{array}$ & 0.59 & $0.15-2.23$ & 2.35 & $0.69-8.06$ & 1.23 & $0.39-3.82$ \\
$\begin{array}{l}\text { Minimum adequate diet } \\
\text { (N=320) }\end{array}$ & 0.76 & $0.14-4.08$ & 0.58 & $0.11-3.02$ & 0.95 & $0.21-4.33$ \\
\hline
\end{tabular}

Complementary feeding variables were selected based on PAHO et al. (2013) IYCF recommendations

$\mathrm{AOR}=$ adjusted odds ratio

${ }^{*} \mathrm{P}=<0.05$

${ }^{* *} \mathrm{P}=<0.01$

\section{DISCUSSION}

More than half (54.1\%) of the respondents introduced complementary foods at an appropriate age, and this exceeds a $31 \%$ prevalence of timely complementary feed introduction reported in Nasarawa, Nigeria (Awogbenja and Ugwuona, 2010). However other studies from several countries reported similar prevalence of timely complementary feed introduction in Taiwan (50\%) (Lin et al., 2011) and West Bengal, India (55.1\%) (Sinhababu et al., 2010). Timely complementary feeding has been reported to contribute to prevention of stunting and promotion of optimal growth, health and behavioral development in middle- and low-income countries (Black et al., 2013; WHO, 2017).

The prevalence of continued breastfeeding at one year $(30.8 \%)$ in this study was far lower than national reports from Nigeria (82.9\%) but compares well with that of United State of America (35.3\%) (NPC and ICF 2019; CDC, 2020). Thus, study finding contradicts the Lancet (2016) reports that continued breastfeeding is much more common in low- and middle-income countries than it is in high-income countries (Victora et al., 2016). 
In the present study, high prevalence $(62.5 \%)$ of minimum dietary diversity attained among children 6-23 months compares well with a study from one city in India (Singhal et al. 2015) which reported $>70 \%$. However, lower ranges were reported in 2018 Nigeria Demographic and Health Survey (NDHS) (22.6\%) and other studies (13-46\%) (NPC and ICF, 2019; Bentley et al., 2015; Mukhopadhyay et al., 2013; Mondal et al., 2014; Parashar et al., 2015). Poor dietary diversity is a common practice in poor populations because the main complementary diets are mainly starch based staples, with few animal products and vegetables (Arimond and Ruel, 2004). The observed high dietary diversity among the respondents may be attributed to the involvement of educated and working mothers in this study as they are knowledgeable and buoyant enough to afford diverse foods particularly vegetables, legumes and nuts, eggs and fleshy foods.

However, the minimum meal frequency was observed to be low in this study $(31.9 \%)$, this corroborates with findings (32-44.7\%) from several studies (Mondal et al., 2014; Bentley et al., 2015; Singhal et al., 2015; Aemro et al., 2011 and Rao et al., 2011). Similar observation was also found in the 2018 NDHS data (41.8\%) (NPC and ICF, 2019). A plausible explanation for the observed low feeding frequency is the little time mothers have available to care for their children due to their workload.

The prevalence of minimum adequate diet among 6-23 month-old children in the current study is low, at $22.5 \%$. Similarly, WHO found that less than one-fourth of children aged 6-23 months met the minimum acceptable diet (MAD) in several countries (WHO, 2005), while Nigeria DHS reported an even lesser prevalence (11.0\%) (NPC and ICF, 2019)

The prevalence of stunting, wasting and underweight in this study $(11.3 \%, 12.5 \%$ and $8.3 \%$ respectively) does not compare well with reports from Nigeria Demographic and Health Survey, which found $37 \%, 27.2 \%$ and $23.0 \%$ respectively (NPC and ICF, 2019).

The United Nations Standing Committee on Nutrition asserted that the prevalence of acute malnutrition between 5\% and $8 \%$ indicates a worrying nutritional situation, and prevalence $>10 \%$ corresponds to a serious situation (UNSCN, 2008). This indicates that despite the low numbers observed, the wasting and underweight prevalence in this study depicts a worrisome nutrition situation and hence deserves attention.

The higher prevalence of malnutrition among males over females as shown in this study have been previously reported in other studies (Adeladza, 2010; Disha et al., 2012). This weakens the evidence that the girl child in developing countries is less prioritized in care, health, education and other opportunities.

In this study, stunting was found to be higher for older children as over one-tenth $(10.7 \%)$ and one-fifth (21.3\%) of children aged 6-8 and 13-23 months respectively were reported to be stunted. This agrees with national reports which revealed a stunting prevalence of $21.9 \%$ and 41.4\% amongst children aged 6-8 and 18-23 months respectively (NPC and ICF, 2019). Stunting being a proxy for chronic malnutrition (Cogil, 2003; NPC and ICF, 2009; Ojofeitimi et al., 2003), might by this finding be implying that the observed elevated stunting prevalence in older groups could be an outcome of nutritional deprivation in the child's first year of life. 
Wasting prevalence was higher in infants (aged 6-12 months) than young children (aged 13-24 months). This could be attributed to the challenges encountered during the transition from breastmilk to complementary feeding introduction which normally occurs within 6-12 months of a child's life.

Observed low stunting risk in currently breastfeed children corroborates with reports by Matee et al. (1997) who established that continued breastfeeding at one year was protective against stunting and wasting (odds ratio, 0.8). Therefore, efforts should be intensified to ensure that continued breastfeeding awareness and advocacy receives as much attention as exclusive breastfeeding.

That minimum dietary diversity had a significant association with a nutritional status indicator was previously documented studies in some studies (Hatloy et al., 2000; Ruel et al., 2004). Nigerian traditional complementary foods which are typically monotonous in nature--mainly starchy roots, tubers and cereal-based porridges have been reported to be unable to meet the energy and nutrient needs of infants and young children (Yusufu et al., 2013; Ibeanu, 2009; Onoja and Obizoba, 2009). Improving the variety of complementary goods using locally available food stuffs is vital to ensuring optimal nutritional status of children.

\section{CONCLUSIONS}

The complementary feeding practices of the respondents is not commendable, as only two out of five complementary feeding recommendations -timely complementary feeding and minimum dietary diversity, were met by more than half of the respondents. Although the under-nutrition situation of these children was considerably lower than the national figures, wasting and underweight prevalence of children in Abakaliki exceeded the public health significance thresholds for under 5 children. The odds for under-nutrition, especially stunting, was found to be lower in children currently fed breast-milk at one year and quality/diverse complementary foods. Therefore, promotion of continued breastfeeding at one year and diversification of complementary foods using locally available/affordable foods should gain more visibilitity at all maternal and child health programs and interventions.

\section{Acknowledgements:}

The authors wish to thank all the support staff of the Institute and Child Health, and Alex Ekwueme Federal University Teaching Hospital Abakaliki for their cooperation and assistance. 


\section{REFERENCES}

Adeladza A (2010). The influence of socio-economic and nutritional characteristics on child growth in Kwale District of Kenya. African Journal of Food, Agriculture, Nutrition and Development 9(7):1570-1590. doi: 10.4314/ajfand.v9i7.47686

Aemro M, Mesele M, Birhanu Z, et al. (2013). Dietary diversity and meal frequency practices among infant and young children aged 6-23 months in Ethiopia: A secondary analysis of Ethiopian Demographic and Health Survey 2011. Journal of Nutrition and Metabolism 2013, Article ID 782931. doi: 10.1155/2013/782931

Aggarwal A, Verma S and Faridi MM (2008). Complementary feeding-reasons for inappropriateness in timing, quantity and consistency. Indian Journal of Pediatrics 75(1):49-53. doi: 10.1007/s12098-008-0006-9

Amsalu S and Tigabu Z (2008). Risk factors for severe acute malnutrition in children under the age of five: A case-control study. Ethiopian Journal of Health Development 22:21-25. doi: 10.4314/ejhd.v22i1.10058.

Arimond M and Ruel MT (2004). Dietary diversity is associated with child nutritional status: evidence from 11 demographic and health surveys. Journal of Nutrition 134(10):2579-2585. doi: $10.1093 / \mathrm{jn} / 134.10 .2579$

Atimati AO and Adam VY (2019). Infant and young child feeding practices and nutritional status of children (0-24 months) in Egor LGA, Edo State Nigeria. Nigerian Journal Nutritional Sciences 40:1-11.

Awogbenja MD and Ugwuona FU (2010). Feeding practices and nutritional status of under-five children in Nasarawa State, Nigeria. Production Agriculture and Technology6(1):23-35.

Ayogu RN, Ibeanu VN and Ene-Obong HN (2015). Infant feeding and anthropometric failure in infants (0-2 years) in Nsukka District of Enugu State, Nigeria. Nigerian Journal of Nutritional Sciences 36:47-57.

Black RE, Victora CG, Walker SP, et al. (2013). Maternal and child undernutrition and overweight in low-income and middle-income countries. Lancet 382(9890):427-5. DOI: S01406736(13)60937-X

Bentley A, Das S, Alcock G, et al. (2015). Malnutrition and infant and young child feeding in informal settlements in Mumbai, India: Findings from a census. Food Science and Nutrition 3:257-271. doi: 10.1002/fsn3.214.

Center for Disease Control and Prevention. Breastfeeding Report Card 2020, United States: outcome indicators. Atlanta, USA: Center for Disease Control and Prevention; 2020. https://www.cdc.gov/breastfeeding/data/reportcard.htm 
Cogill B (2003). Anthropometric Indicators Measurement Guide. Washington, D.C: Food and Nutrition Technical Assistance Project (FANTA), Academy for Educational Development. https://www.fantaproject.org/tools/anthropometry-guide

De Onis M, Garza C, Onyango AW, et al. (2006). WHO Child Growth Standards. Acta Paediatrica 450:1-11. doi: 10.1080/08035320500495548

Dewey KG and Vitta B S (2013). Strategies for Ensuring Adequate Nutrient Intake for Infants and Young Children during the Period of Complementary Feeding. A\&T Technical Brief, Issue 7. Washington, D.C: Alive and Thrive.

Dewey, KG and Adu-Afarwuah S (2008). Systematic review of the efficacy and effectiveness of complementary feeding interventions in developing countries. Maternal Child Nutrition 4:24-85. doi: 10.1111/j.1740-8709.2007.00124.x.

Disha AD, Rawat R, Subandoro A, et al. (2012). Infant and young child feeding (IYCF) practices in Ethiopia and Zambia and their association with child nutrition: analysis of demographic and health survey data. African Journal of Food, Agriculture, Nutrition and Development 12(2):5895-5914.

Federal Ministry of Health (2005). National policy on infant and young child feeding in Nigeria. Nigeria: Abuja. https://www.health.gov.ng

Hatloy A, Halland J, Diarra M, et al. (2000). Food variety, socioeconomic status and nutritional status in urban and rural areas in Koutiala, Mali. Public Health Nutrition 3:57-65. doi: 10.1017/ s1368980000000628.

Ibrahim UA, Gboluwaga AT and Iliyasu Z (2019). Mothers' feeding practices and nutritional status of infants in a rural community in Kano state north-west Nigeria. Journal of Medicine in the Tropics 21:93-99. doi: 10.4103/jomt.jomt_26_19

Iheme GO, Nzeagwu OC, Uzokwe CA, et al. (2021). A meta-analysis of compliance with revised WHO-infant and young child feeding indicators in data generation. Clinical Nutrition ESPEN 43:169-173. doi: 10.1016/j.clnesp.2021.03.016

Jamro B, Junejo AA, Lal S, et al. (2012). Risk factors for severe acute malnutrition in children under the age of 5 years in Sukkur. Pakistan Journal of Medical Research 51:111-113.

Krebs NF, Hambidge, KM, Mazariegos M, et al. (2011). Complementary feeding: a global network cluster randomised controlled trial. BMC Pediatrics 11(4):4-14. doi: 10.1186/14712431-11-4.

Krishnan A, Ng N, Kapoor S K, et al. (2012). Temporal trends and gender differentials in causes of childhood deaths at Ballabgarh, India-need for revisiting child survival strategies. BMC Public Health 12:555-564. doi: 10.1186/1471-2458-12-555. 
Kruger R and Gericke GA (2003). qualitative exploration of rural feeding and weaning practices, knowledge and attitudes on nutrition. Public Health Nutrition 6(2):217-223. doi:

10.1079/PHN2002419.

Lawoyin TO, Onadeko MO and Kolude O (2003). Risk factors for malnutrition among under-5year-old in an inner city community in Ibadan: A case-control study. Nigerian Journal of Paediatrics 30:7-12. doI: 10.4314/njp.v30i1.12038.

Lin JR, Tzeng MS, Kao MD, et al. (2011). Practice to introduce complementary foods to infants in Taiwan - changes from 1997 to 2008. Asian Pacific Journal of Clinical Nutrition 20(2):337345

Matee M I, Msengi A E, Simon E, et al. (1997). Nutritional status of under 5 attending maternal and child health clinics in Dares Salaam, Tanzania. East African Medical Journal 74(6): 368-371.

Mondal T, Sarkar A, Shivam S, et al. (2014). Assessment of infant and young child feeding practice among tribal women in Bhatar block of Burdwan district in West Bengal, India. International Journal of Medical Science and Public Health 3:324-326. https://imsear.searo.who.int/handle/123456789/153331.

Mukhopadhyay DK, Sinhababu A, Saren AB, et al. (2013) Association of child feeding practices with nutritional status of under-two slum dwelling children: A community-based study from West Bengal, India. Indian Journal of Public Health 57:169-172. https://www.ijph.in/text.asp?2013/57/3/169/119819

Mushaphi L, Mbhenyane X, Khoza L, et al. (2008). Infant-feeding practices of mothers and the nutritional status of infants in the Vhembe District of Limpopo Province. South African Journal of Clinical Nutrition 21(2):36-41. doi: 10.1080/16070658.2008.11734159.

National Population Commission and ICF (2019). Nigeria Demographic and Health Survey 2018 Key Indicators Report. Abuja, Nigeria, and Rockville, Maryland, USA: NPC and ICF 2019. https://www.dhsprogram.com/pubs/pdf/FR359/FR359.pdf

Ndiokwelu CI, Maduforo AN, Amadi CA, et al. (2014). Breastfeeding and Complementary Feeding Practices of Mothers of Children ( $0-24$ Months) attending Infant Welfare Clinice (IWC) at the Institute of Child Health (ICH) University of Nigerian Teaching Hospital (UNTH) Ituku-Ozalla Enugu. Journal of Biology, Agriculture and Healthcare 4:5-15.

Odunayo S I and Oyewole AO (2006). Risk factors for malnutrition among rural Nigerian children. Asia Pacific Journal of Clinical Nutrition 15:491-495.

Ojofeitimi EO, Owolabi OO, Aderonmu A, et al. (2003). A study on under five nutritional status and its determinants in a semi-rural community of Ile-Ife, Osun State, Nigeria. Nutrition and Health 17:21-27. doi: 10.1177/026010600301700103. 
Okereke I, Obeagu EI, Ovute AO, et al. (2015). Complementary Feeding Practices And Nutritional Values of Complementary Foods Used By Igbo Mothers of Imo and Abia States Of Nigeria. European Journal of Pharmaceutical and Medical Research 2:185-208.

Oluwaseyi A, Tunrayo $\mathrm{O}$ and Omotola $\mathrm{T}$ (2019). Feeding and weaning practices among mothers of under-five children in selected primary health care centres in Ado-Ekiti, Ekiti, Nigeria. Potravinarstvo Slovak Journal of Food Sciences 14:42-51. doi: 10.5219/1211.

Omotoye FE and Adesanmi RA (2019). Infant and Young Child-Feeding Practices in Two Local Government Areas in Southwest, Nigeria. Journal of Food Science and Nutrition Research 2:136-145. doi: 10.26502/jfsnr.2642-11000015.

PAHO, WHO, UNICEF (2013). ProPAN: Process for the Promotion of Child Feeding. 2nd ed. Washington, D.C.: Pan American Health Organization. https://www.paho.org/hq/dmdocuments/2013/Propan2-Eng.pdf

Parashar A, Sharma D, Thakur A, et al. (2015). Infant and young child feeding practices Insights from a cross-sectional study in a hilly state of North India. International Journal of Nutrition, Pharmacology and Neurological Diseases 5:103-107. doi: 10.5219/1211.

Plessis LM, Kruger HS and Sweet L (2013). Complementary feeding: a critical window of opportunity from six months onwards. South African Journal of Clinical Nutrition 26(3):129140.

Rao S, Swathi P, Unnikrishnan B, et al. (2011). Study of complementary feeding practices among mothers of children aged six months to two years - A study from coastal South India. Australasian Medical Journal 4:252-257. doi: 10.4066/AMJ.2011.607

Sarkar R, Sivarathinaswamy P, Thangaraj B, et al. (2013). Burden of childhood diseases and malnutrition in a semi-urban slum in southern India. BMC Public Health 13:87-102. doi: 10.1186/1471-2458-13-87.

Singhal P, Garg SK, Chopra H, et al. (2013). Status of infant and young child feeding practices with special emphasis on breast feeding in an urban area of Meerut. IOSR Journal of Dental and Medical Sciences 7:7-11.

Sinhababu A, Mukhopadhyay DK, Panja TK, et al. (2010). Infant- and young child-feeding practices in Bankura District, West Bengal, India. Journal of Health, Population and Nutrition 28(3):294-296. doi: 10.3329/jhpn.v28i3.5559.

Sosanya M, Gbemileke A, Freeland-Graves J, et al. (2019). Determinants of Infant and Young Child Feeding Practices of Rural Farming Households in Bauchi State, Nigeria. Current Developments in Nutrition 3(1):108-119. doi: 10.1093/cdn/nzz039.P18-108-19. 
Tobi NS, Alex-Hart BA and George IO (2019). Effect of Infant and Young Child Feeding Practices on the Nutritional Status of Children 0-24 Months of Age in Port Harcourt, Nigeria. Asian Journal of Medicine and Health 17:1-21. doi: 10.9734/ajmah/2019/v17i430170.

UNSCN (2008). United Nations System Standing Committee on Nutrition, Interpretation of indicators; (Working group report). Bull World Health Organ 64:929-941.

Victora G, Bahl B, Barros AJ, et al. (2016). The Lancet Breastfeeding Series Group. Breastfeeding in the 21 st century: epidemiology, mechanisms, and lifelong effect. Lancet 387:475-490. doi: 10.1016/S0140-6736(15)01024-7.

WHO (2005). The global burden of disease: 2004 update. Geneva. https://www.who.int/healthinfo/global_burden_disease/2004_report_update/en/ WHO (2006). WHO Child Growth Standards. Length/Height-for-Age, Weight-for-Age, Weightfor-Length, Weight-for-Height and Body Mass Index-for-Age: Methods and Development. Geneva. https://www.who.int/publications/i/item/924154693X

WHO (2017). Complementary Feeding; Biological, behavioral and contextual rationale. https://www.who.int/elena/titles/bbc/complementary feeding/en

WHO (2018). Infant and young child feeding Geneva. http://www.who.int/news-room/factsheets/detail/infant-and-young-child-feeding

Yamane T (1967). Sample size determination involving the use of prevalence from previpos study, desired level of precision and confidence level. 1967.

Yusuf T and Jibrin B (2020). Complementary feeding practices and nutritional status of young children in a community in Sokoto. Nigerian Journal Paediatrics 47 (4):324-329. doi: 10.4314/njp.v47i4.5. 